\title{
Composição Física da Carcaça de Bezerros da Raça Holandesa Alimentados com Dietas Contendo Diferentes Níveis de Concentrado
}

\section{Ricardo Dias Signoretti ${ }^{1}$, Gherman Garcia Leal de Araújo², José Fernando Coelho da Silva ${ }^{3}$, Sebastião de Campos Valadares Filho ${ }^{3}$, Paulo Roberto Cecon 4}

\begin{abstract}
RESUMO - O objetivo deste estudo foi avaliar o efeito dos diferentes níveis de concentrado nas dietas sobre a composição física da carcaça. Trinta e dois bezerros da raça Holandesa, PC, variedade preto e branco, divididos em dois grupos de abate (grupo 1: 16 animais abatidos com $190 \pm 10 \mathrm{~kg}$ PV e grupo 2: 16 animais abatidos com $300 \pm 10 \mathrm{~kg}$, com, em média, 75 dias de idade e $78 \mathrm{~kg}$ PV inicial, foram distribuídos em delineamento inteiramente casualizado, com quatro tratamentos e quatro repetições para ambos os grupos. Os animais foram alimentados à vontade com dietas contendo 45,0; 60,0; 75,0; e 90,0\% de concentrado na base da ração (\% MS), usando-se feno de capim coast-cross (Cynodon dactylon), fubá de milho e farelo de soja, os quais constituíram dietas com aproximadamente $16 \% \mathrm{~PB}$. A cada período de 28 dias, os animais foram pesados e abatidos quando se aproximavam do peso de abate preestabelecido para os grupos 1 e 2 . A proporção de ossos na carcaça dos animais do grupo 1 não foi influenciada, porém a de músculos diminuiu e a de gordura e as relações tecido adiposo:ósseo e tecido adiposo:muscular aumentaram linearmente, em função dos níveis de concentrado nas rações. O aumento do nível de concentrado nas rações influenciou somente a relação tecido muscular:ósseo na carcaça dos animais do grupo 2.
\end{abstract}

Palavras-chave: dieta-completa, gordura, músculo, osso, relação volumoso:concentrado

\section{Carcass Physical Composition of Holstein Calves Fed Diets with Different Levels of Concentrate}

\begin{abstract}
The objective of this study was to evaluate the effect of different dietary levels of concentrate on the carcass physical composition. Thirty two pure Holstein black and white type bull calves, into two slaughter groups (group 1: 16 animals slaughtered with $190 \pm 10 \mathrm{~kg}$ PV and group 2: 16 animals slaughtered with $300 \pm 10 \mathrm{~kg}$ ) with average of 75 days of age and initial $75 \mathrm{~kg}$ LW were allotted to a completely randomized design, with four treatments and four replicates for both groups. The animals were full fed diets containing 45.0, 60.0, 75.0, and 90.0\% concentrate in the diet (\% DM), using coast-cross (Cynodon dactylon) grass hay, corn meal and soybean meal, which constituted diets with approximately $16 \% \mathrm{CP}$. At each 28 days period, the animals from each group were weighed and slaughtered at preestablished weights for the groups 1 and 2. The increase of the concentrate levels in the diets only affected proportion of bone in the carcass of the animals of group 1, were not affected, however that of muscle decreased and that of fat, adipose tissue:bone ratio and adipose tissue:muscle ratio linearly increased with the concentrate levels in the diets. The increase of dietary concentrate levels only influenced the muscle:bone ratio in the carcass of the animals of the group 2 .
\end{abstract}

Key Words: complete diet, fat, muscle, bone, forage to concentrate ratio

\section{Introdução}

O objetivo do estudo da composição física das carcaças é a avaliação de parâmetros diretamente relacionados com os aspectos qualitativos e quantitativos de sua porção comestível. A prioridade é a criação de animais capazes de direcionar grandes quantidades da energia alimentar para a produção de músculos, produzindo carcaças com elevada proporção de carne comercializável.

Dentro desse contexto, destacam-se os bezerros da raça Holandesa que, criados em sistemas intensi- vos e abatidos em idade precoce, apresentam grande potencial para ganhar peso e produzir carne de excelente qualidade. Contudo, o nível de concentrado nas dietas, pelo seu conteúdo energético, é a porção responsável pela engorda dos animais e um dos constituintes mais onerosos nos custos operacionais de um confinamento. A determinação de seu nível ótimo, objetivando produção de carcaças com alta proporção de carne, é uma maneira do pecuarista conseguir maximizar a produtividade e lucratividade do rebanho.

Entre os principais fatores que influem na taxa de crescimento e na composição física da carcaça,

\footnotetext{
1 Engenheiro Agrônomo, Doutor em Zootecnia.

2 Pesquisador do CPATSA - EMBRAPA. 56300-000 Petrolina, PE.

3 Professor do DZO/UFV e bolsista do CNPq. 36571-000 Viçosa, MG

${ }^{4}$ Professor do Departamento de Matemática da UFV.
} 
relacionam-se a idade cronológica, a idade fisiológica (condição sexual, estádio de maturidade, peso corporal), o nível nutricional (efeito da dieta sobre a eficiência de utilização de energia e proteína), a raça, o estado hormonal, o "turnover" relativo dos tecidos, o número e a atividade celular (DNA), as condições ambientais (efeito do calor e, ou frio) (GILL e OLDHAM, 1993; OWENS et al., 1995).

Em termos de peso, os principais tecidos que constituem a carcaça dos animais domésticos são muscular, adiposo e ósseo. A ordem de prioridade na formação destes três tecidos, de acordo com a maturidade fisiológica e em escala decrescente, é ósseo, muscular e adiposo (MÜLLER e PRIMO, 1986).

O desenvolvimento destes tecidos não ocorre de forma isométrica. A velocidade de crescimento dos diferentes tecidos do corpo terá maior impulso em uma fase diferente da vida do animal.

A proporção de ossos na carcaça diminui lentamente, à medida que o peso do animal aumenta, constituindo no tecido sujeito a menor variação percentual. Os músculos representam alta porcentagem do peso total ao nascimento, que aumenta ligeiramente e começa a decrescer à medida que se inicia a fase de deposição de gordura.

Long, em 1973, citado por GALVÃO (1991), mostrou variações na porcentagem de tecido muscular entre 37 e $67 \%$, na proporção de gordura de 20 a $45 \%$ e no teor de ossos de 12 a $16 \%$, em bovinos.

O tecido muscular, inicialmente, e depois o tecido adiposo exercem grande influência na composição da carcaça, enquanto os ossos em nenhum estádio têm papel dominante na determinação das proporções relativas dos três tecidos (BERG e BUTTERFIELD, 1976).

MARPLE (1983) relatou que a porcentagem de músculos permaneceu relativamente constante até o ponto em que o animal atingiu, aproximadamente, metade do peso de mercado. A partir da segunda fase de crescimento, a porcentagem de gordura da carcaça aumentou mais rapidamente e a porcentagem de músculos começou a decrescer continuamente.

OSÓRIO et al. (1994) verificaram, em bovinos da raça Holandesa abatidos com pesos vivos (PV) de 375 a $550 \mathrm{~kg}$, crescimento ósseo em ritmo mais lento, do tecido adiposo mais rápido e dos músculos em ritmo igual ao do PV. Os mesmos autores observaram redução na proporção de ossos, aumento na gordura da carcaça e manutenção da proporção dos músculos com aumento do PV.

A gordura foi uma fração importante, pois influenciou diretamente o aspecto visual da carcaça, o rendimento da porção comestível e a qualidade da carne (MOLETTA e RESTLE, 1996). A precocidade em termos de deposição de gordura foi variável conforme a raça, a condição sexual, a idade e o nível nutricional. Além disso, foi uma característica importante em sistemas de produção de bovinos de corte, criados mais intensivamente, em que os animais foram abatidos com menos idade, pois foi o fator que mais contribui para a redução do rendimento dos cortes comerciais, devendo o peso de abate dos animais coincidir com o ponto de maturidade momento em que a gordura está em nível desejável (BERG e BUTTERFIELD, 1976; ROBELIN, 1986).

Com relação ao efeito do nível nutricional sobre a composição física da carcaça, ROHR e DAENICKE (1984) relataram que o aumento na ingestão de energia pode aumentar o ganho de carcaça, bem como a porcentagem de gordura na carcaça.

WALDMAN et al. (1971) verificaram, em estudo da composição de carcaça de novilhos da raça Holandesa submetidos à alimentação com diferentes níveis de energia na dieta, que os animais alimentados com dieta contendo nível elevado de energia apresentaram maior crescimento de tecido adiposo na carcaça em relação aos músculos, porém dieta contendo nível moderado de energia resultou em crescimento na mesma proporção para os tecidos adiposo e muscular.

No que tange ao efeito da condição sexual, as fêmeas tendem a depositar maior proporção de gordura e menor proporção de carne que os machos castrados, e estes, por sua vez, mais que animais nãocastrados (STEEN, 1995).

Os bovinos da raça Holandesa apresentaram, em geral, carcaças com menores proporções de gordura, com menor índice de marmorização (gordura entre as fibras musculares) e maior porcentagem de músculos que animais de raças zebuínas (VELLOSO et al., 1975).

A relação músculo:osso foi utilizada na classificação dos animais segundo sua habilidade para produzir carne (ROBELIN e GEAY, 1983).

BERG e BUTTERFIELD (1976) afirmaram que a relação músculo:osso se elevou com o aumento do peso do animal. A queda da porcentagem de ossos foi verificada com o aumento do peso vivo, em virtude de o desenvolvimento máximo do tecido ósseo ocorrer em fase mais precoce da vida do animal.

HANKINS e HOWE (1946) afirmaram que a relação músculo:osso, devido ao seu efeito direto sobre o rendimento de carne comestível, foi de grande importância. Entretanto, BERG e BUTTERFIELD (1976) asseguraram que o verdadeiro fator 
Rev. bras. zootec.

determinante da relação músculo:osso foi mais o peso da carcaça que a adiposidade.

Segundo Geay e colaboradores, em 1976, citados por ROBELIN e GEAY (1983), o nível alimentar não teve efeito sobre a relação músculo:osso, quando foram comparados animais de mesmo peso vivo.

ROBELIN e GEAY (1983) relataram que a proporção entre músculo e osso aumentou de $2,3-2,4$ ao nascimento para 4,5 - 5,6 em animais de $500-600 \mathrm{~kg}$ de peso corporal vazio.

O objetivo do presente estudo foi avaliar a composição física (proporções de músculos, gordura e ossos) da carcaça de bezerros da raça Holandesa submetidos a sistema de alimentação à vontade, em que a dieta total continha $45 ; 60 ; 75$; e $90 \%$ de concentrado.

\section{Material e Métodos}

Conduziu-se o experimento nas dependências do Laboratório Animal do Departamento de Zootecnia da Universidade Federal de Viçosa, Minas Gerais.

Foram utilizados 32 bezerros da raça Holandesa, puros por cruzamento, não-castrados, com idade média de 75 dias e peso vivo médio inicial de $78 \mathrm{~kg}$, sendo 16 para o grupo $1(190 \pm 10 \mathrm{~kg}$ de peso vivo ao abate) e 16 para o grupo $2(300 \pm 10 \mathrm{~kg}$ de peso vivo ao abate), alimentados "ad libitum". As dietas utilizadas foram constituídas de feno de capim coast-cross (Cynodon dactylon), previamente picado, fubá de milho, farelo de soja, calcário e mistura mineral, formuladas para atender as exigências de energia e proteína, segundo as normas do NRC (1989), para ganho de peso vivo esperado de $1,0 \mathrm{~kg} /$ dia.

As dietas apresentaram níveis crescentes de concentrado de $45,60,75$, e $90 \%$, cuja composição químico-bromatológica se encontra na Tabela 1.

As dietas foram fornecidas, em uma refeição diária, às 7h30, à vontade, ajustando-se sobra diária em torno de $10 \%$ do oferecido, por animal, e registrandose a ingestão durante todo o período experimental.

Antes de iniciar o período de adaptação de 15 dias, todos os animais foram devidamente identificados com brincos, pesados e tratados contra ecto e endoparasitos e receberam, ainda, vitamina ADE injetável, ao início e a cada 60 dias de permanência no confinamento.

Ao atingirem os pesos preestabelecidos de $190 \pm 10 \mathrm{~kg}$ (grupo 1) e $300 \pm 10 \mathrm{~kg}$ (grupo 2), os animais foram abatidos com jejum prévio de 16 horas e acesso à água. Após o abate, os pesos do sangue, do couro, da cabeça, dos pés, da cauda, do trato
885

Tabela 1-Teor de MS, MO, PB, EE, NDT, CHOT, FDN, Ca, P, $\mathrm{Mg}, \mathrm{Ke} \mathrm{Na}$

Table 1 - Conten of DM, OM, CP, EE, TDN, TCH, NDF,Ca, P, Mg, $\mathrm{K}$ and $\mathrm{Na}$

\begin{tabular}{|c|c|c|c|c|}
\hline \multirow[t]{2}{*}{ Item } & \multicolumn{4}{|c|}{$\begin{array}{c}\text { Nível de concentrado (\%) } \\
\text { Level of concentrate }\end{array}$} \\
\hline & 45 & 60 & 75 & 90 \\
\hline$\overline{\mathrm{MS}}(D M), \%$ & 87,51 & 87,39 & 87,45 & 87,43 \\
\hline $\mathrm{MO}(O M)^{1}$ & 95,46 & 95,81 & 96,23 & 96,41 \\
\hline $\mathrm{PB}(C P)^{1}$ & 15,68 & 15,48 & 15,79 & 15,68 \\
\hline $\mathrm{EE}^{1}$ & 1,90 & 2,71 & 2,89 & 3,01 \\
\hline $\operatorname{NDT}(T D N)^{1}$ & 69,67 & 73,33 & 76,33 & 82,00 \\
\hline $\mathrm{CHOT}(T C H)^{1}$ & 77,33 & 77,10 & 77,05 & 77,20 \\
\hline $\operatorname{FDN}(N D F)^{1}$ & 52,91 & 41,94 & 32,88 & 24,27 \\
\hline $\mathrm{Ca}^{1}$ & 0,55 & 0,52 & 0,51 & 0,54 \\
\hline $\mathrm{P}^{1}$ & 0,22 & 0,25 & 0,20 & 0,20 \\
\hline $\mathrm{Mg}^{1}$ & 0,13 & 0,13 & 0,12 & 0,11 \\
\hline $\mathrm{K}^{1}$ & 1,45 & 1,28 & 1,06 & 0,92 \\
\hline $\mathrm{Na}^{1}$ & 0,10 & 0,13 & 0,12 & 0,16 \\
\hline
\end{tabular}

Matéria seca (MS), matéria orgânica (MO), proteína bruta (PB), extrato etéreo (EE), nutrientes digestíveis totais (NDT), carboidratos totais (CHOT) e fibra em detergente neutro (FDN).

Dry matter (DM), organic matter (OM), crude protein (CP), ether extract (EE), total digestible nutrients (TDN), total carbohydrates (TCH) and neutral detergent fiber (NDF).

1 Porcentagem da MS (Percentage in DM).

gastrintestinal vazio, da gordura interna, do mesentério, do fígado, do coração, dos rins, do baço, do pulmão, da língua, do esôfago, da traquéia e do aparelho reprodutor foram registrados.

A carcaça foi dividida em duas metades, sendo estas pesadas individualmente e resfriadas por 18 horas, à temperatura de $-5^{\circ} \mathrm{C}$. Utilizando-se a metade esquerda, foi retirada a secção transversal, incluindo a $9^{\mathrm{a}}, 10^{\mathrm{a}}$ e $11^{\mathrm{a}}$ costelas, secção $\mathrm{HH}$, segundo HANKINS e HOWE (1946). Na secção HH, determinaram-se as proporções de músculo, tecido adiposo e ossos, estimando-se as proporções correspondentes na carcaça, por meio das seguintes equações desenvolvidas por HANKINS e HOWE (1946):

Músculo: $\hat{Y}=16,08+0,80 X$

Gordura: $\hat{Y}=3,54+0,80 X$

Osso: $\quad \hat{Y}=5,52+0,57 X$

em que

$\mathrm{X}$ é a porcentagem do componente na secção HH.

Utilizou-se o delineamento experimental inteiramente casualizado, com quatro tratamentos e quatro repetições para ambos os grupos. Realizaram-se análises de variância e regressão na interpretação das variáveis estudadas, usando-se o programa computacional SAEG (Sistema de Análises Estatísticas 
e Genéticas), desenvolvido por EUCLYDES (1983). Os coeficientes de regressão foram comparados pelo teste "t", adotando-se os níveis de 5 e 10\% de probabilidade.

\section{Resultados e Discussão}

As proporções de tecido muscular, adiposo e ósseo e as relações entre os mesmos, na carcaça, estimadas com base nos valores obtidos na secção $\mathrm{HH}$, utilizando-se as equações propostas por HANKINS e HOWE (1946), em função dos níveis de concentrado nas dietas, para os animais do grupo 1 (190 kg de PV) e 2 (300 kg de PV), encontram-se, respectivamente, nas Tabelas 2 e 3 .

Os animais abatidos com $190 \mathrm{~kg}$ de PV, alimentados com dietas contendo 75 e $90 \%$ de concentrado apresentaram menor $(\mathrm{P}<0,05)$ porcentagem de tecido muscular na carcaça e maior $(\mathrm{P}<0,05)$ de tecido adiposo. Resultados semelhantes foram obtidos por WALDMAN et al. (1971), BOND et al. (1972), ROHR e DAENICKE (1984) e JONES et al. (1985), que constataram maiores teores de gordura na carcaça de animais que receberam dietas à base de concentrado em relação aos que foram alimentados com dietas à base de volumoso. Além disso, após a desmama, o crescimento do tecido muscular ocorre em taxas relativamente altas, desacelerando-se em estádio mais avançado do desenvolvimento, enquanto a proporção de tecido adiposo é pequena por ocasião do nascimento, mas sua taxa de crescimento aumenta à medida que o animal se desenvolve (BERG e BUTTERFIELD, 1976).

Com relação à porcentagem de tecido ósseo na carcaça, não foram evidenciados efeitos dos níveis de concentrado, para animais do grupo 1, o qual apresentou proporção média de $18,51 \%$. Este resultado está de acordo com Long, em 1973, citado por GALVÃO (1991), o qual relatou que o tecido ósseo apresentou pequena variação percentual. Além disso, BERG e BUTTERFIELD (1976) e MARPLE (1983) relataram que o maior impulso no crescimento do tecido ósseo ocorreu em fase mais precoce da vida do animal.

Os resultados encontrados no presente trabalho foram próximos dos encontrados por BOND et al. (1972), que constataram proporção média de tecido ósseo de 19,0\% em bovinos da raça Holandesa em crescimento.

Não houve diferença quanto às relações tecido muscular:ósseo (RMO) e tecido mole:ósseo (RTMO), para animais do grupo 1 (Tabela 2), porém as relações tecido adiposo:ósseo (RTAO) e tecido

Tabela 2 - Média, regressão ajustada para as proporções de tecido muscular (TM), adiposo (TA) e ósseo (TO) e relações tecido muscular:ósseo (RMO), tecido mole ${ }^{1}$ :ósseo (RTMO), tecido adiposo:ósseo (RTAO), tecido adiposo:muscular (RTAM), nas carcaças dos animais do grupo 1 (190 kg PV)

Table 2 - Means, fitted regression for the proportion of muscle tissue (MT), adipose (AT) and bone (BT) and, muscle tissue:bone (MTO), soft tissue ${ }^{1}$ :bone (STO), adipose tissue:bone (ATO), adipose tissue:muscle (ATM) ratios, in the animal carcass, of group $1(190 \mathrm{~kg} \mathrm{LW})$

\begin{tabular}{|c|c|c|c|c|c|c|}
\hline \multirow{3}{*}{$\begin{array}{l}\text { Tecido } \\
\text { Tissue }\end{array}$} & \multicolumn{4}{|c|}{ Nível de concentrado (\%) } & \multirow[t]{3}{*}{$\mathrm{CV} \%$} & \multirow{3}{*}{$\begin{array}{l}\text { Regressão } \\
\text { Regression }\end{array}$} \\
\hline & \multicolumn{4}{|c|}{ Level of concentrate } & & \\
\hline & 45 & 60 & 75 & 90 & & \\
\hline \multicolumn{7}{|c|}{ Proporção (\%) } \\
\hline \multicolumn{7}{|c|}{ Proportion } \\
\hline $\mathrm{TM}(M T)$ & 62,93 & 60,83 & 56,51 & 58,14 & 4,85 & 1 \\
\hline $\mathrm{TA}(A T)$ & 18,19 & 20,53 & 24,38 & 24,08 & 12,15 & 2 \\
\hline $\mathrm{TO}(B T)$ & 18,70 & 18,54 & 18,87 & 17,92 & 6,15 & $\hat{\mathrm{Y}}=18,51$ \\
\hline \multirow{2}{*}{\multicolumn{7}{|c|}{$\begin{array}{l}\text { Relação entre os tecidos } \\
\text { Relation among tissues }\end{array}$}} \\
\hline & & & & & & \\
\hline $\operatorname{RMO}(M T O)$ & 3,40 & 3,29 & 3,00 & 3,26 & 9,64 & $\hat{Y}=3,24$ \\
\hline $\operatorname{RTMO}(S T O)$ & 4,37 & 4,40 & 4,29 & 4,61 & 8,22 & $\hat{\mathrm{Y}}=4,42$ \\
\hline $\operatorname{RTAO}(A T O)$ & 0,99 & 1,12 & 1,29 & 1,35 & 13,87 & 3 \\
\hline$\underline{\operatorname{RTAM}}(A T M)$ & 0,29 & 0,34 & 0,44 & 0,42 & 15,68 & 4 \\
\hline 1. $\hat{\mathrm{Y}}=68,0090-0,12455^{\star} \mathrm{NC}$ & & & & & & $r^{2}=0,72$ \\
\hline 2. $\hat{\mathrm{Y}}=12,1080+0,14348 * \mathrm{NC}$ & & & & & & $r^{2}=0,87$ \\
\hline 3. $\hat{\mathrm{Y}}=0,6202+0,00836^{*} \mathrm{NC}$ & & & & & & $r^{2}=0,96$ \\
\hline 4. $\hat{\mathrm{Y}}=0,1585+0,003133^{*} \mathrm{NC}$ & & & & & & $\mathrm{r}^{2}=0,82$ \\
\hline
\end{tabular}

* Significativo $(\mathrm{P}<0,05)$ pelo teste de "t" ("Significant at $(P<.05)$ by "t" test).

$\mathrm{NC}=$ Nível de concentrado nas dietas $(\%)$ (Level of concentrate in the diets).

${ }^{1}$ Tecido mole $=$ Tecido muscular $($ TM $)+$ tecido adiposo $($ TA $)($ Soft tissue $=$ Muscle tissue (MT) + adipose tissue (AT). 
Rev. bras. zootec.

Tabela 3 -Média, regressão ajustada para as proporções de tecido muscular (TM), adiposo (TA) e ósseo (TO) e relações tecido muscular:ósseo (RMO), tecido mole ${ }^{1}$ :ósseo (RTMO), tecido adiposo:ósseo (RTAO), tecido adiposo:muscular (RTAM), nas carcaças, dos animais do grupo 2 (300 kg PV)

Table 3 - Mean, fitted regression for proportion of muscle tissue (MT), adipose (AT) and bone (BT) and, muscle tissue:bone (MTO), soft tissue ${ }^{1}$ :bone (STO), adipose tissue:bone (ATO), adipose tissue: muscle (ATM) rations, in the animals carcass, of group 2 (300 kg LW)

\begin{tabular}{|c|c|c|c|c|c|c|}
\hline \multirow{3}{*}{$\begin{array}{l}\text { Tecido } \\
\text { Tissue }\end{array}$} & \multirow{2}{*}{\multicolumn{4}{|c|}{$\begin{array}{l}\text { Nível de concentrado }(\%) \\
\text { Level of concentrate }\end{array}$}} & \multirow[t]{3}{*}{$\mathrm{CV} \%$} & \multirow{3}{*}{$\begin{array}{l}\text { Regressão } \\
\text { Regression }\end{array}$} \\
\hline & & & & & & \\
\hline & 45 & 60 & 75 & 90 & & \\
\hline \multicolumn{7}{|c|}{ Proporção (\%) } \\
\hline \multicolumn{7}{|c|}{ Proportion } \\
\hline TM $(M T)$ & 51,05 & 59,83 & 58,09 & 57,36 & 9,40 & 1 \\
\hline $\mathrm{TA}(A T)$ & 30,09 & 24,85 & 26,20 & 25,90 & 18,41 & $\hat{\mathrm{Y}}=26,76$ \\
\hline $\mathrm{TO}(B T)$ & 18,69 & 13,42 & 16,45 & 17,18 & 19,87 & 2 \\
\hline \multicolumn{7}{|c|}{ Relação entre tecidos } \\
\hline \multicolumn{7}{|c|}{ Relation among tissues } \\
\hline $\mathrm{RMO}(M T O)$ & 2,73 & 4,12 & 3,58 & 3,35 & 19,95 & 3 \\
\hline $\operatorname{RTMO}_{(S T O)}$ & 4,35 & 4,22 & 5,16 & 4,87 & 20,84 & $\hat{\mathrm{Y}}=4,65$ \\
\hline $\operatorname{RTAO}(A T O)$ & 1,62 & 1,53 & 1,59 & 1,53 & 18,83 & $\hat{\mathrm{Y}}=1,56$ \\
\hline RTAM $(A T M)$ & 0,59 & 0,44 & 0,47 & 0,45 & 26,89 & $\hat{\mathrm{Y}}=0,49$ \\
\hline \multirow{3}{*}{\multicolumn{6}{|c|}{ 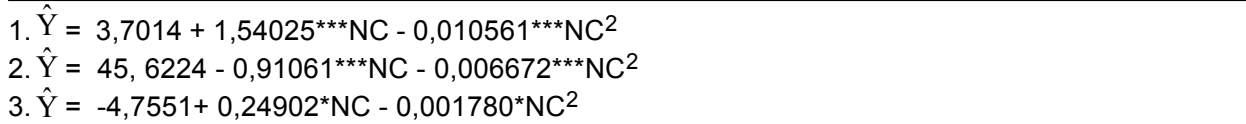 }} & $R^{2}=0,85$ \\
\hline & & & & & & $\mathrm{R}^{2}=0,62$ \\
\hline & & & & & & $\mathrm{R}^{2}=0,74$ \\
\hline
\end{tabular}

adiposo:muscular (RTAM) aumentaram linearmente $(\mathrm{P}<0,05)$ em função dos níveis de concentrado. Estes resultados refletem, basicamente, as mudanças nas proporções de músculos e gordura e a permanência relativamente constante na proporção de ossos na carcaça. Conseqüentemente, o aumento na proporção de gordura na carcaça, com adição de concentrado nas dietas, refletiu decisivamente no aumento da RTAO e RTAM.

Geay e colaboradores, em 1976, citados por ROBELIN e GEAY (1983), relataram que o nível alimentar não teve efeito sobre a relação músculo:osso, quando se compararam animais de mesmo peso vivo.

Observou-se comportamento quadrático para as proporções de músculos e ossos na carcaça de animais abatidos com $300 \mathrm{~kg}$ de PV, estimando-se proporção máxima de 59,86\% e mínima de $14,56 \%$ para os níveis de 72,92 e $68,24 \%$ de concentrado, respectivamente, para o tecido muscular e ósseo.

Quanto à porcentagem de tecido adiposo na carcaça dos animais do grupo 2, embora houvesse tendência de maior proporção de gordura em animais alimentados com dietas contendo $45 \%$ de concentrado, não houve diferenças entre os níveis de concentrado estudados. Isto pode ser explicado, provavelmente, pelo fato de os animais alimentados com dietas contendo $45 \%$ de concentrado terem permanecido por maior período no confinamento (229 dias) em relação aos que receberam dietas contendo $90 \%$ de concentrado, que permaneceram 199 dias no confinamento, para que pudessem atingir o peso de abate preestabelecido de $300 \mathrm{~kg}$.

A gordura influiu no rendimento da porção comestível da carcaça, no seu aspecto visual e na qualidade da carne. Animais mais jovens acumularam menores proporções de tecido adiposo que os adultos (MÜLLER e PRIMO, 1986). Quanto maior a quantidade de gordura na carcaça, menor a proporção de músculos, ou seja, há correlação negativa entre músculos e gordura (BERG e BUTTERFIELD, 1976).

Não houve diferença quanto às RTMO, RTAO e RTAM, para animais do grupo 2, com adição de concentrado na dieta (Tabela 3 ).

Observou-se comportamento quadrático para RMO na carcaça dos animais do grupo 2, estimando-se relação máxima de 3,95 para o nível de 69,93\% de concentrado na dieta. Este fato pode ser explicado pelo aumento e redução nas proporções de músculos e ossos, respectivamente, na carcaça de animais alimentados com dietas contendo $60 \%$ de concentrado. 


\section{Conclusões}

A proporção de músculos e gordura na carcaça de animais abatidos com $190 \mathrm{~kg}$ de PV, respectivamente, diminuiu e aumentou linearmente, enquanto a de ossos não foi influenciada pela adição de concentrado nas dietas.

As relações tecido adiposo:ósseo e tecido adiposo:muscular, para os animais abatidos com $190 \mathrm{~kg}$ de PV, aumentaram linearmente em função dos níveis de concentrado na dieta.

As proporções de músculos e ossos e a relação músculo:osso na carcaça de animais abatidos com $300 \mathrm{~kg}$ de PV apresentaram comportamento quadrático, enquanto a proporção de tecido adiposo não foi influenciada pela inclusão de concentrado nas dietas.

\section{Referências Bibliográficas}

BERG, R.T., BUTTERFIELD, R.M. 1976. New concepts of cattle growth. New York: Sydney University. 240p.

BOND, J., HOOVEN JR, N.W., WARICK, E. et al.1972 Influence of breed and plane of nutrition on performance of dairy, dualpurpose and beef steers. II. From 180 days of age to slaughter. J. Anim. Sci., 34(6):1046-53.

EUCLYDES, R.F. 1983. Manual de utilização do programa SAEG (Sistema para Análises Estatísticas e Genéticas). Viçosa - MG. 59p.

GALVÃO, J.G.C. Estudo da eficiência nutritiva, características e composição física da carcaça de bovinos de três grupos raciais, abatidos em três estágios de maturidade. Viçosa, MG: UFV, 1991, 82p. Dissertação (Mestrado em Zootecnia) - Universidade Federal de Viçosa, 1991.

GILL, M., OLDHAM, J.D. 1993. Growth. In: FORBES, J.M., FRANCE, J.(Eds.). Quantitative aspects of ruminant digestion and metabolism. Cambridge: $\mathrm{CAB}$ International. $515 \mathrm{p}$.

HANKINS, O.G., HOWE, P.E. 1946. Estimation of the composition of beef carcasses and cuts. Washington, D. C. (Tech. Bulletin - USDA, 926).

JONES, S.D.M., ROMPALA, R.E., JEREMIAH, L.E. 1985. Growth and composition of the empty body in steers of different maturity types fed concentrate or forage diets. $J$. Anim. Sci., 60(2):427-433.

MARPLE, D.N. Principles of growth and development. In: GROWTH MANAGEMENT CONFERENCE, 1983, Indiana. Proceedings... Indiana: IMC, 1983. p.1-6.
MOLETTA, J.L., RESTLE, J. 1996. Características de carcaça de novilhos de diferentes grupos genéticos terminados em confinamento. R. Soc. Bras. Zootec., 25(5):876-888.

MÜLLER, L., PRIMO, A.T. 1986 Influência do regime alimentar no crescimento e terminação de bovinos e na qualidade da carcaça. Pesq. Agropec. Bras., 21(4):445-452.

NATIONAL RESEARCH COUNCIL - NRC. 1989. Nutrient requirements of dairy cattle. 6.ed. Washington, D.C. 157p.

OSÓRIO, J.C., JARDIM, P.O., SIEWERDT, F. et al. Desenvolvimento da composição tecidual da carcaça em bovinos holandês. In: REUNIÃO ANUAL DA SOCIEDADE BRASILEIRA DE ZOOTECNIA, 31, 1994, Maringá. Anais... Maringá: SBZ, 1994, p.186.

OWENS, F.N., DONALD, R.G., SECRIST, D.S. et al. 1995. Review of some aspects of growth and development of feedlot cattle. J. Anim. Sci., 73:3152-3172.

ROBELIN, J. 1986. Growth of adipose tissues in cattle; partitioning between depots, chemical composition and cellularity: a review. Livest. Prod. Sci., 14(4):349-364.

ROBELIN, J., GEAY, Y. 1983. Body composition of cattle as affected by physiological status, breed, sex and diet. In: GILCHRIST, F.M.C., MACKIE, R.I. (Eds.). Herbivore nutrition in the subtropics and tropics. Pretoria, Soulth Africa: The Science Press. p.525-548.

ROHR, K., DAENICKE, R. 1984. Nutritional effects on the distribution of live weight as gastrointestinal tract fill and tissue components in growing cattle. J. Anim. Sci., 58(3):753-765.

STEEN, R. W. J. 1995. The effect of plane of nutrition and slaughter weigth on growth and food efficiency in bull, steers and heifers of three breed crosses. Livest. Prod. Sci., 42(1):1-11.

VELLOSO, L., SILVA, L.R.M., BOIN, C. et al. 1975. Desenvolvimento de bovinos mestiços Holandeses inteiros e castrados, em regime de confinamento e as características das carcaças. Bol. Ind. Anim., 32(1):37-45.

WALDMAN, R.C., TYLER, W.J., BRUNGARDT, V.H. 1971. Changes in the carcass composition of Holstein steers associated with ration energy levels and growth. J. Anim. Sci., 32:611.
Recebido em: 27/08/98

Aceito em: 25/01/99 